\title{
Techno-Economic Analysis of Intermittent Renewable Energy Penetration with the Proposed India-Sri Lanka HVDC Interconnection
}

\author{
Asanka S. Rodrigo and Dilini V. Fernando
}

\begin{abstract}
This paper presents a techno-economic analysis to identify the level of intermittent renewable energy (RE) such as wind \& solar penetration in to the Sri Lankan power system with the proposed India-Sri Lanka HVDC interconnection. This research adopts a methodology to identify the level of RE penetration with the HVDC link and compares with original power system planned with a pumped storage power plant. Future power plant additions based on least cost principles were derived using WASP software considering a staged development of the interconnection; 500MW in 2025 and 1000MW in 2028. This power plant schedule was input to long term dispatch simulation software SDDP and short term dispatch simulation software NCP to simulate the dispatch and obtain excess generation from renewable to calculate the RE penetration level. The economic analysis was carried out to identify the cost impact and it was observed that the interconnection is economical for the initial RE capacities. RE penetration can be increased with the interconnection at an additional cost to the system. Therefore, sensitivity analyse were carried out to identify at what variable cost would the interconnection bring economic benefits to the country.
\end{abstract}

Keywords: $\quad$ HVDC, Intermittent Renewable Energy

\section{Introduction}

Renewable energy (RE) sources for power generation are becoming more popular worldwide. Sri Lanka is also trying to keep up with the trend but being an island nation the system imposes constraints on the level of renewable energy that could be absorbed into the system. Higher intermittent renewable penetration levels may lead to curtailments.

Presently, Sri Lankan Power System has a total installed capacity of about 4000 MW which includes Other Renewable Energy (ORE) namely solar, wind, biomass and mini hydro capacity of $518 \mathrm{MW}$ in addition to major hydro. Recorded peak demand in 2016 was 2453 MW [1]. Sri Lanka power system is operated by Ceylon Electricity Board (CEB). CEB is also the Transmission System Operator. Energy share from ORE in Sri Lankan power sector has reached $10 \%$.

Indian power system consists of $330 \mathrm{GW}$ of Installed capacity of which $82 \%$ is conventional generation and $18 \%$ is renewable based generation. [2] The Government of India has established a target of $175 \mathrm{GW}$ of installed RE capacity by 2022, including $60 \mathrm{GW}$ of wind and $100 \mathrm{GW}$ of solar, up from existing $29 \mathrm{GW}$ wind and 9 GW solar at the beginning of 2017.
Sri Lanka and India have ambitious RE penetration targets. There are about $46 \mathrm{GW}$ of coal power plants operating at low capacity factors which may need to be retired along with the penetration of solar and wind. [3] The energy from such power plants could be imported to Sri Lanka. Hence the HVDC interconnection would bring both countries benefits in terms of renewable energy integration.

\section{Literature Review}

Initial pre-feasibility study on interconnecting the transmission systems of India and Sri Lanka was carried out in 2002[4]. The objective of such a transmission interconnection was to promote bilateral power exchange between the two countries. This interconnection was expected to provide significant benefits to the economies of the two countries through economical power exchange and increased efficiency in system operation.

Eng. (Dr.) Asanka S. Rodrigo, PhD(HKUST)

MSc(Moratuwa), BScEng(Moratuwa), AMIE(Sri Lanka),

Senior Lecturer, Department of Electrical Engineering,

University of Moratuwa, Sri Lanka.

Email:asanka@elect.mrt.ac.lk

Eng. (Ms.) Dilini V. Fernando, BScEng(Peradeniya), AMIE(Sri Lanka), Postgraduate Student, Department of

Electrical Engineering, University of Moratuwa, Sri Lanka. Email:f.dilini@gmail.com 
It has been observed that an electrical grid interconnection could be developed with minor technical challenges and with reasonable investment since the countries are in the same region.

Possible interconnecting locations (substations) in both India and Sri Lanka, different power transmission technologies and transmission interconnection types across the sea have been considered in identifying the alternative transmission interconnections.

Alternatives identified in the feasibility are Madurai-Anuradhapura, Tuticorin-Puttalam and Madurai-Puttalam interconnection using HVDC as well as Madurai-Anuradhapura interconnection using AC with back-to-back DC. For the alternatives using HVDC, the bipolar and monopolar interconnection configurations have been considered.

The study concluded that the proposed transmission interconnection should be fully integrated with generation and transmission expansion plans of the two countries in order to reap the maximum benefit for the total system. Further it was stated that the power system stability studies and reliability studies would be required to assess the real system performance of these alternatives. The alternatives analyzed in the study did not indicate any technical obstacle to build a transmission interconnection between India and Sri Lanka.

The next pre-feasibility study was conducted in 2006 [5]. The study concluded that the crossborder interconnection would benefit to both the countries. An AC interconnection would synchronize the two electrical grids and would bring complexities in frequency control and reactive power control. Therefore, HVDC bipolar connection has been identified as the best option. Considering the difficulty and cost of laying the transmission line including the submarine cables the quantum of power exchange should be significant for the project to be economically viable. Initially $500 \mathrm{MW}$ development and upgrade up to $1000 \mathrm{MW}$ depending on the demand increase has been recommended.

The technical feasibility study for the Project has been completed in September 2011 [6]. The study has evaluated three construction options and two technology options namely current source converter (CSC) and voltage source converter (VSC). The key outcomes of the technical feasibility study are the following.

The interconnection was identified to be high voltage direct current (HVDC), operating at $\pm 400 \mathrm{kV}$, connecting the Madurai $400 \mathrm{kV}$ grid substation in the state of Tamil Nadu, India and the Anuradhapura $220 \mathrm{kV}$ grid substation in the North Central Province, Sri Lanka. The route of the interconnection has been identified as Madurai-Panaikulam (178 km overhead), Panaikulam-Thirukketiswaram $(120 \mathrm{~km}$, submarine) and ThirukketiswaramAnuradhapura (160 km, overhead). The study concluded that the project must be structured as a 1×500 MW mono-polar interconnection.

Rodrigo WDAS et al [7] had done modeling and transient analysis of HVDC bipolar link. They have studied about the dynamic behavior of the DC link and the AC systems in time domain. They have derived the India and Sri Lanka power system in thevenin's equivalent models. Jowsick, A.J.M.I. et al had implemented this interconnection in VSC technology [8]. They have studied the impact from transients due to frequency fluctuation and country blackout on the HVDC transmission line's operations. Further the dynamic performance of the HVDC system has been modeled with detailed inverter side AC network and has been studied about the impact on AC-DC interaction inverter side considering CSC technology [9].

The interconnection has been mathematically modeled in PSCAD/EMTDC software and analysed the system under the steady state condition and perturbed conditions in the paper "Modeling and Simulation of Current Source Converter for Proposed India-Sri Lanka HVDC Interconnection" [10]. This system has been modeled with the basic DC control system and it concludes that the modeled AC-DC interaction is asymptotic stable as it regains the pre-fault operating state after the fault is cleared.

\section{Methodology}

\subsection{Power System Modelling}

Initially the Sri Lankan power system in 2025 and 2028 were developed with and without the interconnection based on the Long Term Generation Expansion Plans. [11] Wien Automation System Package (WASP) software [12] was used in optimizing the generation expansion plan. The 500MW interconnection was considered in 2025 and 1000MW in 2028. 
Initial solar \& wind capacity Projection considered as the starting point of simulation was based on the LTGEP 2018-2037 and given in Table 1.

Table 1 - Solar \& Wind Initial Capacities

\begin{tabular}{|l|l|l|}
\hline & 2025 & 2028 \\
\hline Solar MW & 685 & 900 \\
\hline Wind MW & 730 & 800 \\
\hline
\end{tabular}

Based on the resource estimation, half hourly resource profiles were obtained for five wind regimes and two solar regimes. This was deducted from the half hourly load profiles and the net load was input to the system. The period 2018 to 2028 was considered in the optimization. Annual peak demand considered for the two years of the simulation are as follows;

- For 500 MW HVDC system in 2025: $3836 \mathrm{MW}$

- $\quad$ For 1000 MW HVDC system in 2028: $4398 \mathrm{MW}$

Existing power plant parameters, their respective retirements and candidate power plants parameters was based on draft LTGEP 2018-2037 [11].

Table 2 gives the cost parameters of ORE power plants used in the economic evaluation.

Table 2 - Renewable Power Plant Cost Parameters

\begin{tabular}{|c|c|c|c|c|}
\hline & $\begin{array}{l}\text { Mini } \\
\text { hydro }\end{array}$ & Wind & Solar & Biomass \\
\hline 吾㟥 & 1729 & 1525 & $\begin{array}{l}900.0- \\
1400.0\end{array}$ & 1814.2 \\
\hline 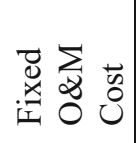 & $\begin{array}{l}3.0 \% \text { of } \\
\text { capital } \\
\text { cost/yr }\end{array}$ & $\begin{array}{l}1.5 \% \text { of } \\
\text { capital } \\
\text { cost/yr }\end{array}$ & $\begin{array}{l}0.7 \% \text { of } \\
\text { capital } \\
\text { cost/yr }\end{array}$ & $\begin{array}{l}2.43 \\
\$ / \mathrm{kW} \\
\text { Month }\end{array}$ \\
\hline 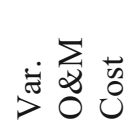 & - & - & - & $\begin{array}{l}4.46 \\
\mathrm{USCts} / \\
\mathrm{kWh}\end{array}$ \\
\hline
\end{tabular}

Source: LTGEP [11]

The interconnection was modeled in WASP as a thermal power plant. HVDC parameters used were based on the 2011 feasibility study as given in Table 3.
Table 3 - HVDC parameters

\begin{tabular}{|l|c|}
\hline Parameter & Value \\
\hline Capacity & $2 \times 500 \mathrm{MW}$ \\
\hline Capital cost & $1286 \$ / \mathrm{kW}$ \\
\hline Construction time & 4 years \\
\hline Plant lifetime & 40 years \\
\hline FOR & $1 \%$ \\
\hline Scheduled maintenance days & 11 \\
\hline Typical losses & $4.5 \%$ \\
\hline Tariff (including wheeling charge) & $70 \mathrm{USD} / \mathrm{MWh}$ \\
\hline
\end{tabular}

Source: [6]

PSPP parameters used are given in Table 4.

Table 4 -PSPP parameters

\begin{tabular}{|l|c|}
\hline \multicolumn{1}{|c|}{ Parameter } & Value \\
\hline Capacity & $3 \times 200 \mathrm{MW}$ \\
\hline Capital Cost & $1291.3 \$ / \mathrm{kW}$ \\
\hline Construction time & 5 years \\
\hline Plant lifetime & 50 years \\
\hline Cycle Efficiency & $70 \%$ \\
\hline Fixed O\&M & 0.83 USD $/ \mathrm{kW}$-month \\
\hline
\end{tabular}

Source: PSPP Feasibility [13]

After obtaining the power plant schedule, it was fed into SDDP [14] to run the long term dispatch simulation to obtain the optimum hydro thermal generation mix. The hydro thermal optimization results were then fed into NCP; the short term dispatch model. The NCP software tool provides the economic dispatch of power plants for systems that comprise hydro, thermal and renewable generation sources. It considers the operational constraints of each type of generation resource and other system operational limitations to conduct the economic dispatch to meet the load [15]. Further when the specified generation constraints cannot be satisfied, the NCP determines the excess amount of electricity generation from renewable energy and calculates the requirement for the curtailments. 


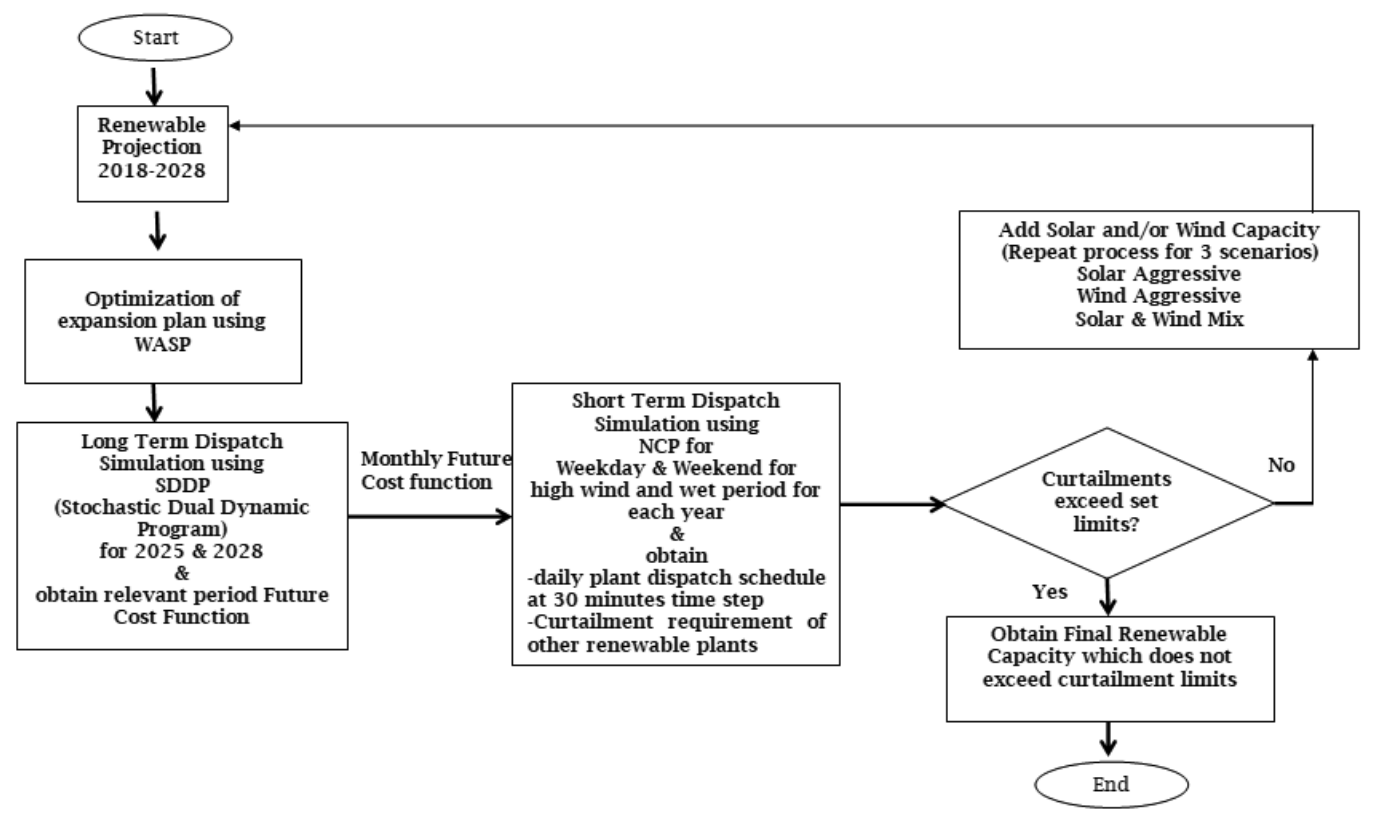

Figure 1 - Methodology

Hydro thermal optimization result obtained from the SDDP simulation which is called future cost function is one of the main inputs for NCP in formulating the daily dispatch simulation. Wet and high wind periods were taken into analysis as they are the limiting criteria for renewable development. Thereafter two days per period, a weekday and a weekend day were selected to represent the demand variations. Renewables modeled were in detail in the dispatch simulation software with 30 minute resolution.

For each simulation representing each season the half hourly generation and the excess renewable outputs were obtained. Solar \& wind capacity development was increased by allowing a curtailment limit of $5 \%$ of demand and the maximum solar and wind capacity were obtained. The process was repeated for each stage of HVDC interconnection development. To analyse the effect of two different technologies solar and wind, this process was repeated for the following scenarios.

- Solar Aggressive scenario

- Wind Aggressive scenario

- Solar \&Wind Mixed scenario

Methodology is depicted in Figure 1.

\subsection{Resource Estimation}

Resource estimation for this research was based on the report "Integration of Renewable Based
Generation into Sri Lankan Grid 2017-2028" [16].

\section{A. Wind}

The report [16] has considered five main wind development zones for the modeling purpose, namely Mannar, Puttalam, Northern, Eastern and Hill Country to capture the diversity of wind portfolios throughout Sri Lanka. Accordingly the 2010-2015 recorded data collected by Sri Lanka Sustainable Energy Authority (SLSEA) have been used for modeling the wind patterns and electricity production of each zone. In cases where complete data sets were not available for 12 months continuously, correlation techniques with the best available data from nearby sites has been used to estimate.

Wind plant modeling to estimate annual electricity production and hourly capacity variation has been carried out using System Advisory Model (SAM 2014.1.14) developed by National Renewable Energy Laboratory, USA.

Hourly wind speed data prepared for each site location is given as an input to the SAM software and then the wind plant is modeled specifying turbine and farm characteristics. Hub height considered for hill country is $50 \mathrm{~m}$ and other sites $80 \mathrm{~m}$. Plant availability of $90 \%$ has been considered. Turbine capacities used and the resulting plant factors for each wind site are given in Table 5. 
Table 5 - Wind Power Plant Parameters \& Results

\begin{tabular}{|c|c|c|c|}
\hline Location & $\begin{array}{c}\text { Block } \\
\text { Capacity }\end{array}$ & $\begin{array}{c}\text { Turbine } \\
\text { Capacity } \\
\text { (MW) }\end{array}$ & $\begin{array}{c}\text { Annual } \\
\text { Plant } \\
\text { Factor }\end{array}$ \\
\hline Mannar & $25 \mathrm{MW}$ & $\begin{array}{c}2.5 \mathrm{MW} \\
\times 10 \\
\end{array}$ & $36.71 \%$ \\
\hline Puttalam & 20MW & $2 \mathrm{MW} \times 10$ & $31.37 \%$ \\
\hline $\begin{array}{c}\text { Hill } \\
\text { Country }\end{array}$ & 10.45MW & $\begin{array}{c}\text { 0.55MW } \\
\text { x19 }\end{array}$ & $19.06 \%$ \\
\hline Northern & 20MW & $2 \mathrm{MW} \times 10$ & $34.07 \%$ \\
\hline Eastern & $20 \mathrm{MW}$ & $2 \mathrm{MW} \times 10$ & $37.32 \%$ \\
\hline
\end{tabular}

\section{B. Solar}

According to the report "Integration of Renewable Based Generation into Sri Lankan Grid 2017-2028" [16] following methodology has been carried out in estimating solar resource profiles.

Solar irradiance measurements have been obtained from the Sri Lanka Sustainable Energy Authority (SLSEA) in two locations namely, Hambantota and Kilinochchi. Global Horizontal Irradiance (GHI) and Diffuse Horizontal Irradiance (DHI) measurements were available with ten minute time step. Direct Normal Irradiance (DNI) has been estimated with the available GHI and DHI using solar zenith angle.

Hourly inputs of solar irradiance measurements $(\mathrm{W} / \mathrm{m} 2)$ has been constructed for a complete year as input to SAM and it was used with site location inputs (latitude, longitude), elevation, and hourly temperature profile of the site. Availability of the plant has been assumed as $90 \%$ and typical commercial PV module and inverter characteristics in built in SAM has been used. Resulted plant factors for the two locations are $16.3 \%$ in Hambanthota and $15.6 \%$ in Killinochchi. [16]

\section{Simulation Results}

\subsection{Optimized Capacity Additions}

For the phase development of interconnection and PSPP the optimized capacity additions were obtained from WASP for the year 2025 and 2028 as shown in Table 6.

4.2 System Comparison with PSPP and interconnection for 500 MW HVDC
With the initial solar and wind capacities of 685 MW and 730 MW respectively the power system with PSPP and interconnection fixed as given in Table 6 was simulated to obtain renewable excess generation. The simulation was carried out using SDDP \& NCP software as described in section 3 .

Simulation results for the wet period in 2025 with 200 MW PSPP are shown in Figure 2 and Figure 3. With $685 \mathrm{MW}$ of solar and $730 \mathrm{MW}$ of wind, curtailments could be observed in wind during off peak hours in the range up to 75 MW. Curtailments of solar were seen during day time of weekend.

Table 6 - Optimized power plant capacity

\begin{tabular}{|c|c|c|c|c|}
\hline 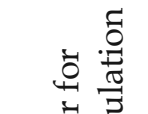 & \multicolumn{2}{|c|}{2025} & \multicolumn{2}{|c|}{2028} \\
\hline & 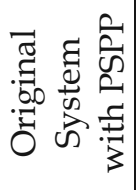 & 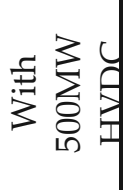 & 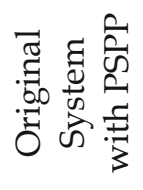 & 要主是 \\
\hline $\begin{array}{l}\text { Major } \\
\text { hydro }\end{array}$ & 1578 & 1578 & 1578 & 1578 \\
\hline $\begin{array}{l}\text { Mini } \\
\text { hydro }\end{array}$ & 424 & 424 & 454 & 454 \\
\hline Biomass & 23.5 & 23.5 & 23.5 & 23.5 \\
\hline Wind & 730 & 730 & 800 & 800 \\
\hline Solar & 685 & 685 & 900 & 900 \\
\hline Thermal & 2344 & 2074 & 2344 & 2074 \\
\hline PSPP & 200 & 0 & 600 & 0 \\
\hline HVDC & 0 & 500 & 0 & 1000 \\
\hline $\begin{array}{l}\text { Total } \\
\text { Installed } \\
\text { Capacity }\end{array}$ & 5985 & 6015 & 6700 & 6830 \\
\hline $\begin{array}{l}\text { Total } \\
\text { Installed } \\
\text { Capacity } \\
\text { without } \\
\text { int. RE* }\end{array}$ & 4146 & 4176 & 4546 & 4676 \\
\hline Demand & 3836 & 3836 & 4398 & 4398 \\
\hline
\end{tabular}

*Solar, wind and mini hydro are Intermittent renewable In the simulation results for 2025 power system (wet period) with HVDC interconnection for the same initial renewable capacities there were no curtailments observed. Dispatch of power plants for weekday and weekend are shown in Figure 4 \& Figure 5. The interconnection causes energy imports during day time \& night peak 
on weekdays and during day peak \& night peak in weekends.

Simulation results for high wind period in 2025 power system with PSPP were also obtained similarly. With $685 \mathrm{MW}$ solar and $730 \mathrm{MW}$ wind capacities, curtailments could be observed but much lesser compared with wet period curtailments.

Simulation results for high wind period in the 2025 power system too did not give rise to curtailments similar to the wet period simulation with interconnection. There are energy imports mainly during night peak time.

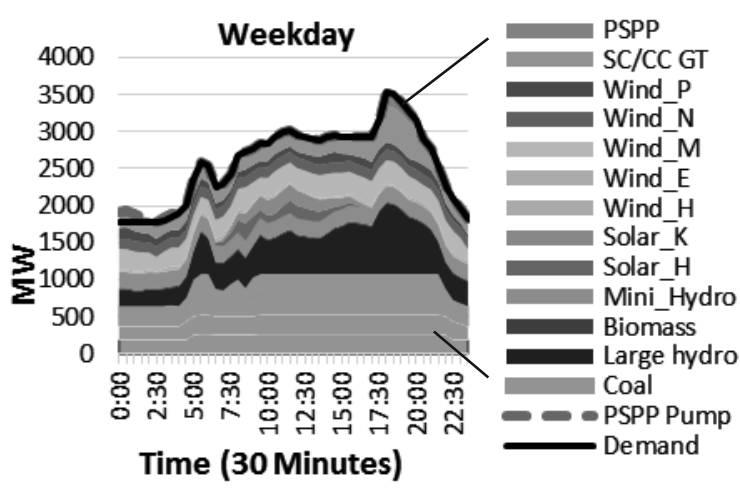

Figure 2 (a): Power plant dispatch with $200 \mathrm{MW}$ PSPP in 2025 wet period weekday

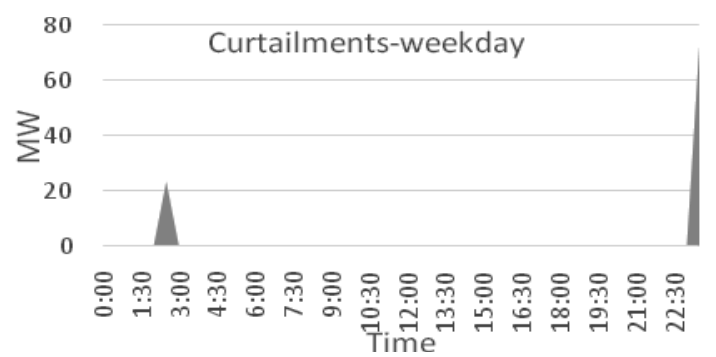

Figure 2 (b): Curtailments of Renewable Generation with 200MW PSPP in 2025 wet period weekday

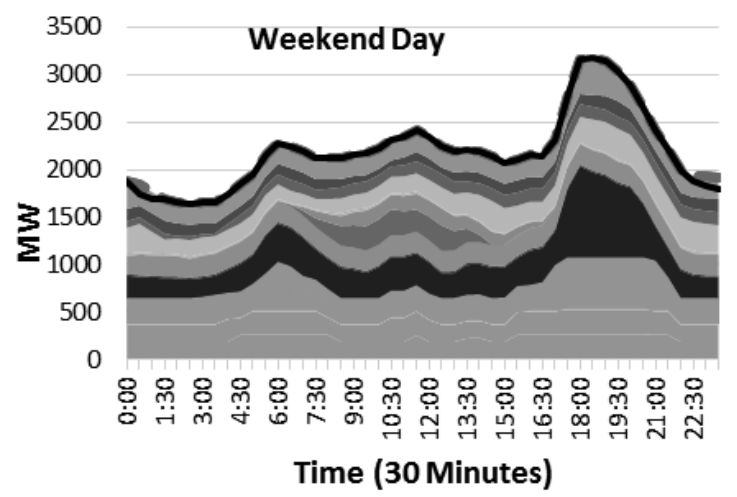

Figure 3 (a): Power plant dispatch with 200MW PSPP in 2025 wet period weekend day

(Figure 2 (a) legend applies)

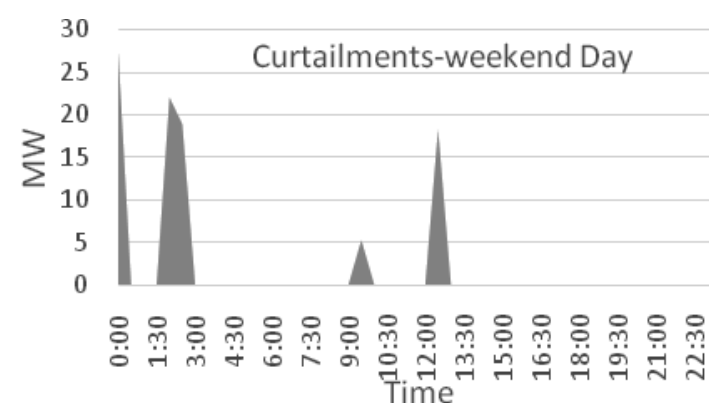

Figure 3 (b): Curtailments of Renewable Generation with 200MW PSPP in 2025 wet period weekend day.

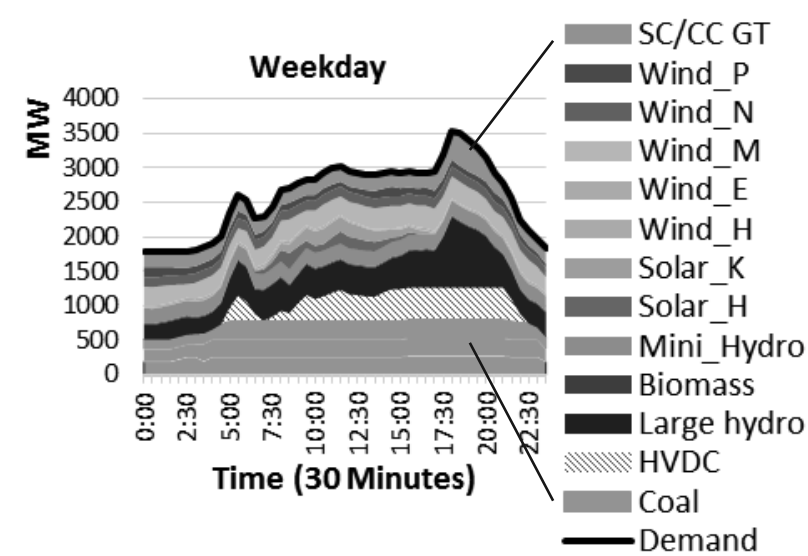

Figure 4: Power plant dispatch with 500MW HVDC in 2025 wet period weekday

(For Figure 5 onwards same legend as Figure 4 applies)

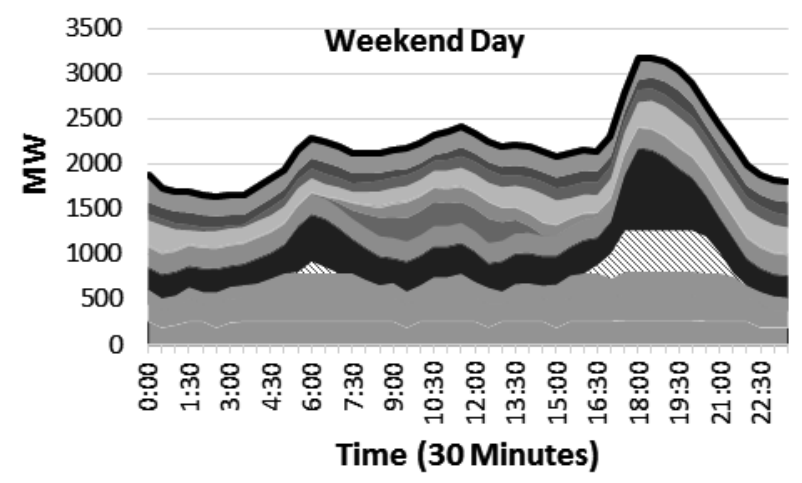

Figure 5: Power plant dispatch with $500 \mathrm{MW}$ HVDC in 2025 wet period weekend

\subsection{Renewable Penetration with Development of 500 MW HVDC in 2025}

Since there were no curtailments in the system with interconnection, solar aggressive, wind aggressive and solar \& wind mix scenarios were separately simulated by increasing renewables.

\section{A. Solar Aggressive Scenario}

In the solar aggressive scenario the original wind capacity of $730 \mathrm{MW}$ was unchanged and the solar capacity was increased until the curtailment limits are reached. 
Simulation results for the wet period are as follows. Solar power capacity could be increased up to $875 \mathrm{MW}$ (addition of $190 \mathrm{MW}$ ) with 500 MW HVDC in the system. The resulting dispatch and curtailment results are shown in Figure 6 and Figure 7.

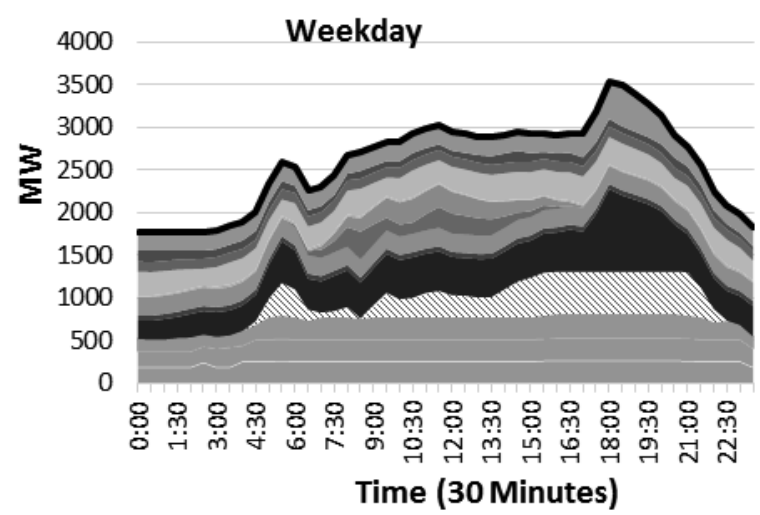

Figure 6 (a): Power plant dispatch with maximum solar penetration with $500 \mathrm{MW}$

HVDC in wet period weekday

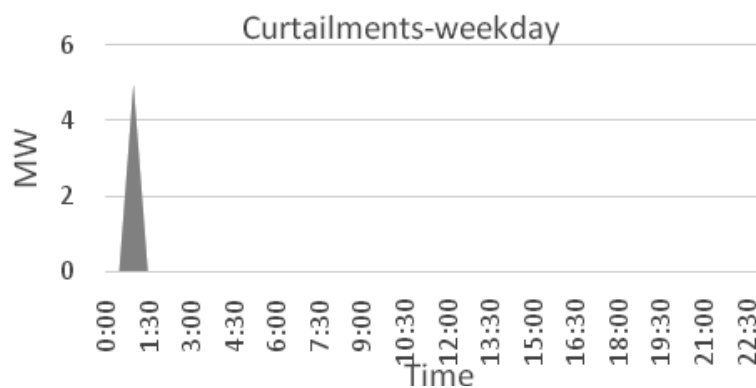

Figure 6 (b): Curtailments with maximum solar penetration with 500MW HVDC in wet period weekday

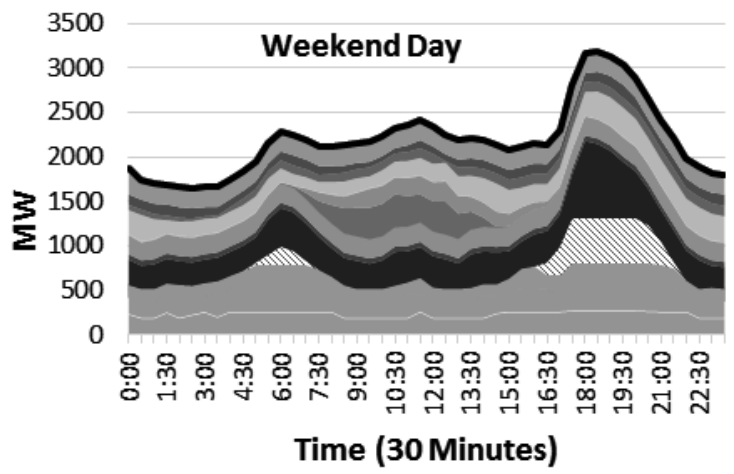

Figure 7 (a): Power plant dispatch with maximum solar penetration with 500MW

HVDC in wet period weekend day

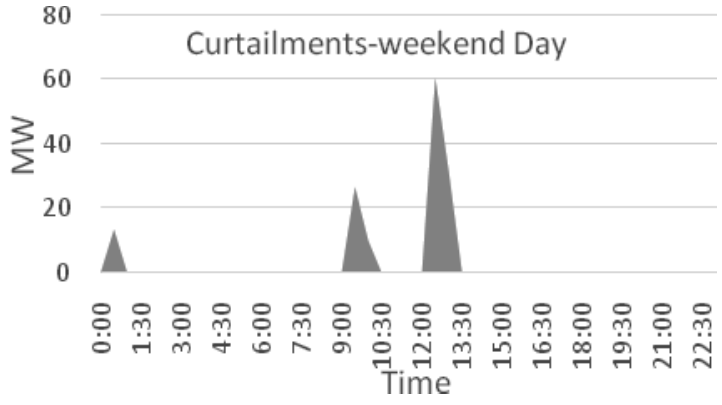

Figure 7 (b): Curtailments with maximum solar penetration with 500 MW HVDC in wet period weekend day

When considering Figure $6(b)$ and $7(b)$, the highest curtailments were observed during day time of a weekend. Therefore solar capacity was increased until weekend day time curtailments are limited to less than 5\% of consumer demand. Final solar capacity was obtained as 875 MW considering the wet period.

Simulation was repeated for high wind period and the final solar capacity was obtained as 885 MW considering the high wind period. It indicates that the annual capacity addition is limited by the dispatch constraints in the wet period.

\section{B. Wind Aggressive Scenario}

In the wind aggressive scenario the original solar capacity of $685 \mathrm{MW}$ was unchanged and the wind capacity was increased until the curtailment limits are reached.

Simulations were carried out for the wet period and the wind capacity could be increased up to $810 \mathrm{MW}$ (addition of $80 \mathrm{MW}$ ). The resulting dispatch and curtailment results are shown in Figure 8 \& Figure 9.

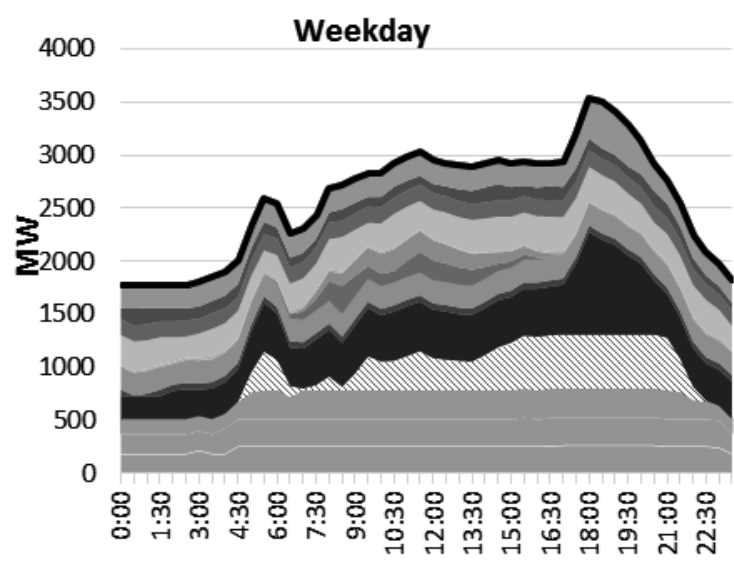

Time (30 Minutes)

Figure 8 (a): Power plant dispatch with maximum wind penetration with 500MW HVDC in wet period weekday 


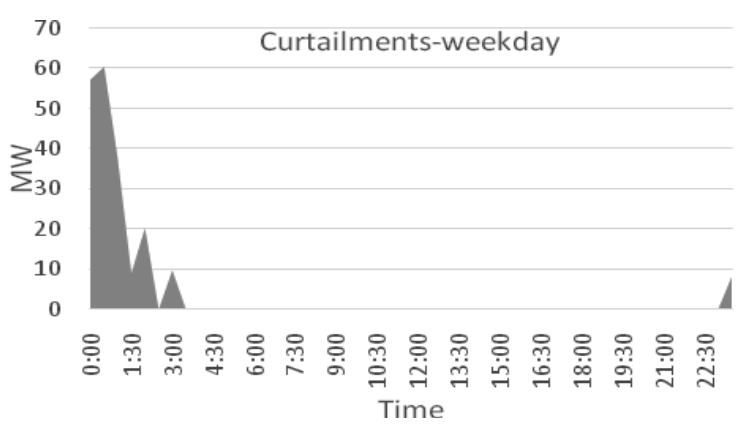

Figure 8 (b): Curtailments with maximum wind penetration with 500MW HVDC in wet period weekday

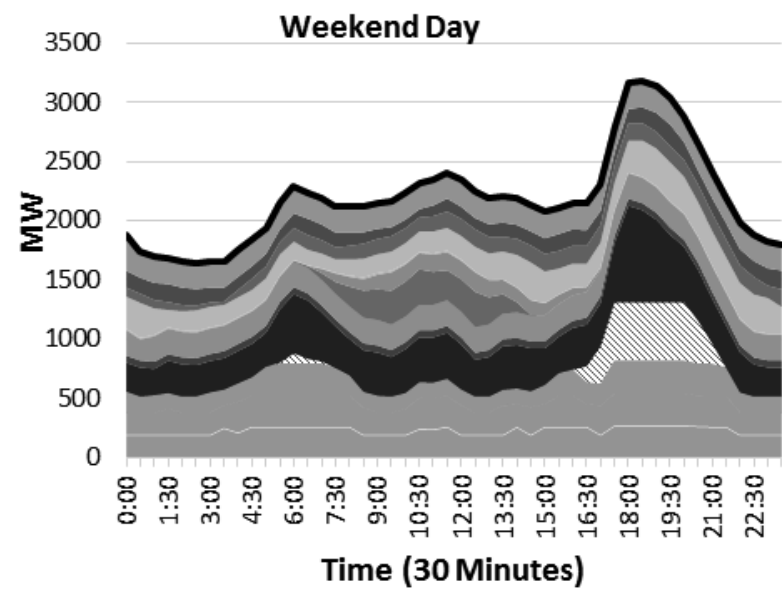

Figure 9 (a): Power plant dispatch with maximum wind penetration with 500MW

HVDC in wet period weekend day

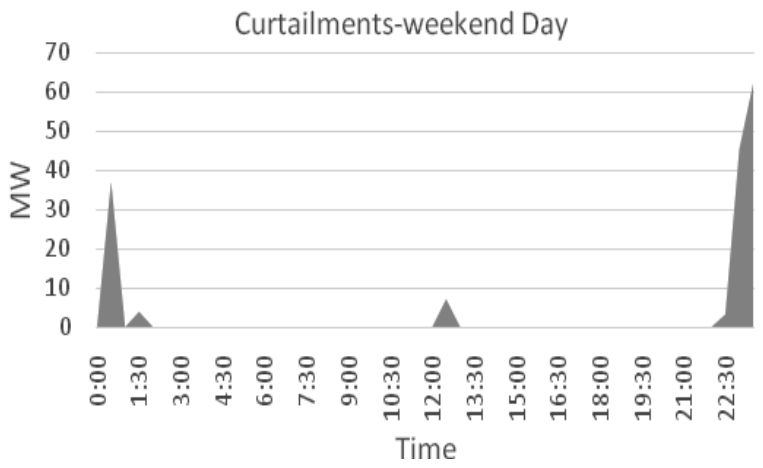

Figure 9 (b): Curtailments with maximum wind penetration with 500MW HVDC in wet period weekend day

When considering Figure 8 (b) \& Figure 9 (b) it could be observed that the highest curtailments in the wind aggressive scenario occur during off peak time. Therefore the wind capacity was increased and dispatch simulations carried out until off peak curtailments are not exceeded 5\% limit. Considering the wet period the final wind capacity was obtained as 810MW.
Simulations were repeated for the high wind period and the cumulative wind capacity was $815 \mathrm{MW}$ which is an addition of $85 \mathrm{MW}$ to the initial capacity. Therefore the final annual capacity was considered as 810 MW considering the limitations in the wet period.

\section{Solar E Wind Mix Scenario}

Similarly, the simulations were carried out for wet and high wind periods for solar and wind mixed development scenario. Final capacities obtained were as $795 \mathrm{MW}$ of solar and $780 \mathrm{MW}$ of wind considering the wet period to limit curtailments.

\subsection{System Comparison with PSPP and interconnection for 1000MW HVDC}

With the initial solar and wind capacities of 900 MW and 800 MW respectively the power system with PSPP and interconnection was simulated to obtain the excess generation from renewable energy.

Similar to with $500 \mathrm{MW}$ HVDC, there were no curtailments observed with 1000 MW HVDC in 2028, although there were curtailments with the PSPP in the original system.

\subsection{Renewable Penetration with Development of 1000 MW HVDC in 2028}

Solar aggressive, wind aggressive and solar \& wind mix scenarios were separately simulated by increasing renewables. Results are given in Table 7.

Table 7 - Solar \& wind capacities with 1000MW HVDC

\begin{tabular}{|l|l|l|}
\hline & Wind MW & Solar MW \\
\hline Initial & 800 & 900 \\
\hline Aggressive solar & 800 & 910 \\
\hline Aggressive wind & 830 & 900 \\
\hline Mixed & 850 & 905 \\
\hline
\end{tabular}

\subsection{Summary of Results}

Figure 10 shows the composition of each solar and wind capacities for the three scenarios with interconnection development.

It could be observed that with 1000 MW HVDC in 2028, a significant capacity could not be increased from the originally planned compared with 500 MW HVDC in 2025. Therefore the second phase of HVDC would not bring many benefits in terms of increasing renewable energy development. 
In Figure 10, 'New wind' and 'New solar' are the additions with the interconnection development. When comparing with the solar aggressive and wind aggressive scenarios in the 2025 power system it can be seen that the wind aggressive scenario has lesser cumulative capacity of solar and wind comparatively.
Depending on the solar and wind capacity mix, the power system with $500 \mathrm{MW}$ interconnection in 2025 could absorb a cumulative solar \& wind capacity of approximately $1500 \mathrm{MW}$ to 1600 MW. This could be increased up to 1750 MW with the $1000 \mathrm{MW}$ interconnection in 2028.

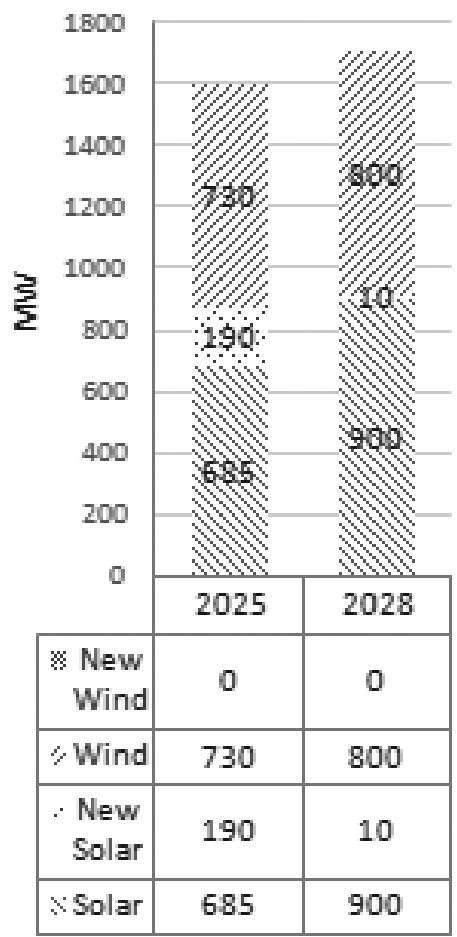

(a) Solar aggressive

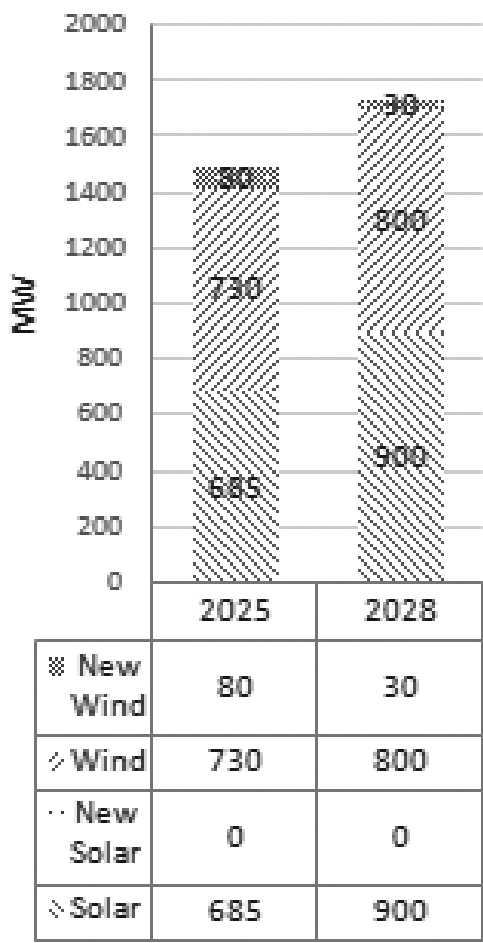

(b) Wind aggressive

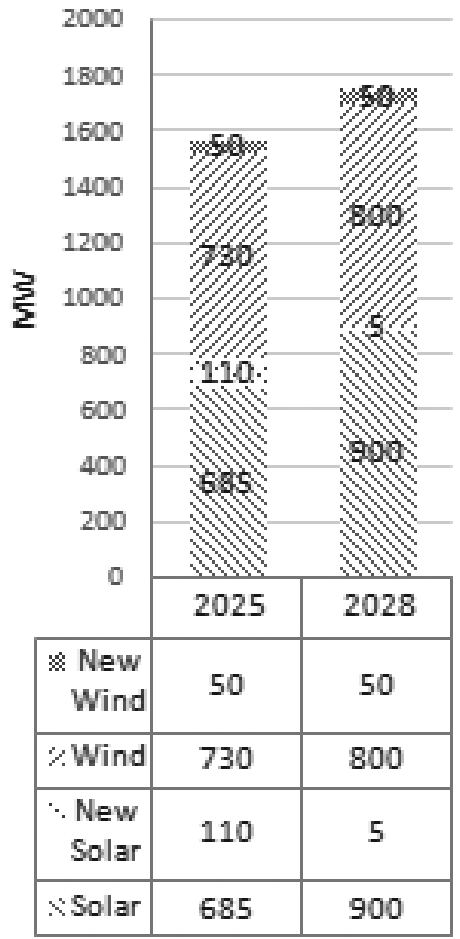

(c) Solar and wind mix

Figure 10 - Summary of renewable capacities

\section{Economic Analysis}

Economic evaluation aims at measuring the economic impact brought about to a country by implementing a project from a viewpoint of the national economy. A comparison of costs expressed in terms of economic costs was used and the Discounted Cash Flow Method was used. Evaluation index obtained was the Present Value (PV) of costs of implementing each one of the scenarios. Phase 1-500MW HVDC development was considered for the economic analysis.

Firstly, a comparison was carried out for the system with the initial solar and wind capacities of $685 \mathrm{MW}$ and $730 \mathrm{MW}$ for the PSPP and interconnection development in 2025 (Scenario 1 \& 2). Then for the scenarios with renewable additions the same $\mathrm{PV}$ cost was analysed (Scenario 3, 4 \& 5). PV of annual costs up to 2025 for each scenario is given in Table 8 .

Scenario 1 - PSPP development scenario with the initial renewable capacity

Scenario 2 - Interconnection development scenario with the initial renewable capacity

Scenario 3 - Interconnection and solar aggressive development

Scenario 4 - Interconnection and wind aggressive development

Scenario 5 - Interconnection and solar \& wind mixed development

When comparing scenarios 1 \& 2, it could be observed that for the initial renewable capacity, the PV cost of the interconnection development scenario is less compared to PSPP development scenario. 
Table 8 - PV Cost of the scenarios in USD million

\begin{tabular}{|l|c|c|c|c|c|}
\hline Scenario & 1 & 2 & 3 & 4 & 5 \\
\hline $\begin{array}{l}\text { PV cost of total investment and } \\
\text { operation of renewable power } \\
\text { plants }\end{array}$ & $1,407.20$ & $1,407.20$ & 1489.00 & 1465.70 & 1486.30 \\
\hline $\begin{array}{l}\text { PV cost of total investment and } \\
\text { operation of other power plants }\end{array}$ & $6,531.34$ & $6,520.71$ & 6512.48 & 6514.10 & 6511.72 \\
\hline Total PV Cost & $7,938.54$ & $7,927.91$ & 8001.48 & 7979.80 & 7998.02 \\
\hline
\end{tabular}

When renewable energy is integrated along with the interconnection, PV cost increases compared with PSPP. The cost difference is given in Table 9.

Table 9 - Cost Difference of Scenarios

\begin{tabular}{|l|l|l|}
\hline & $\begin{array}{l}\text { Total PV cost } \\
\text { USD million }\end{array}$ & $\begin{array}{l}\text { PV Cost } \\
\text { Difference } \\
\text { USD million }\end{array}$ \\
\hline Scenario 1 & $7,938.54$ & - \\
\hline Scenario 2 & $7,927.91$ & $(10.63)$ \\
\hline Scenario 3 & 8001.48 & 62.93 \\
\hline Scenario 4 & 7979.80 & 41.26 \\
\hline Scenario 5 & 7998.02 & 59.48 \\
\hline
\end{tabular}

There is a 10.63 USD million reduction of PV cost in the interconnection scenario compared with PSPP. The wind aggressive scenario has the lowest incremental cost.

A sensitivity analysis was carried out by varying the unit cost of HVDC for each scenario and the PV cost comparison carried out against the PV cost of PSPP scenario.

Figure 11 shows the cost of each scenario for different variable costs of HVDC.

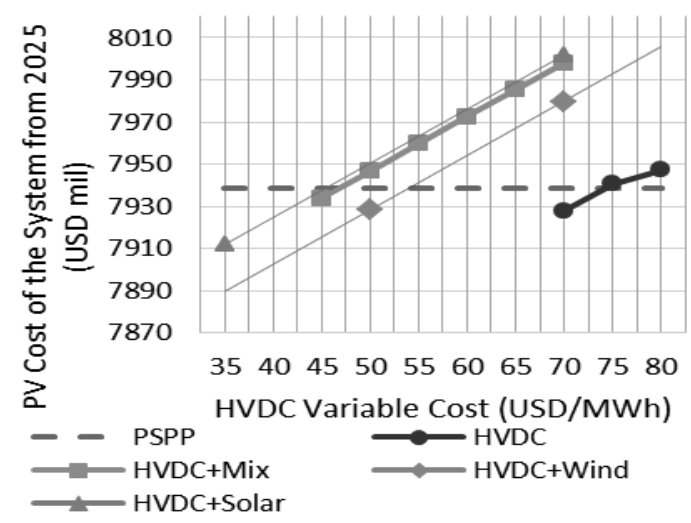

Figure 11 - Variation of PV cost of scenarios with HVDC variable cost
It could be observed that the interconnection scenario with the same solar and wind capacities (685MW solar 730MW wind) as PSPP scenario was economical at $70 \mathrm{USD} / \mathrm{MWh}$. It could be increased up to 74 USD/MWh (11.0 $\mathrm{LKR} / \mathrm{kWh}$ ) to breakeven with the PSPP development scenario.

It could be observed from Figure 11 that the breakeven for the solar aggressive scenario (875MW solar and 730MW wind) occurs at 45 USD/MWh (7.0 LKR/kWh) and for wind aggressive scenario (685MW solar and 810MW) at $54 \mathrm{USD} / \mathrm{MWh}(8.0 \mathrm{LKR} / \mathrm{kWh})$.

In the solar and Wind Mixed Scenario with $795 \mathrm{MW}$ solar and 780MW wind, breaks even at 47 USD/MWh (7.2 LKR/kWh)

\section{Discussion}

The objective of this research was to assess the possible level of incremental penetration of wind and solar power in Sri Lanka with the proposed India-Sri Lanka HVDC interconnection and compare with other options.

When observing the system with PSPP and without PSPP or HVDC interconnection there were curtailments of renewable energy with the initial solar and wind capacities given in Table 1.

The system with interconnection did not give rise to any curtailments since the total thermal power capacity is lower in this scenario compared with PSPP scenario as shown in Table 6. Hence it was observed that the intermittent renewable capacity could be increased further.

Therefore, the simulation process was repeated while renewable capacity was increased limiting the curtailments to $5 \%$ of demand for different scenarios (solar aggressive, wind aggressive and solar \& wind mix) and for 
different stages of HVDC development. To represent seasonal variation wet hydro and high wind periods were considered and to represent the demand variation, weekdays and weekends were considered as samples.

It was observed that in all scenarios, considering the annual capacity addition, the wet period has become the limiting criteria. Due to higher availability of hydro resource the excess generation from renewable energy is higher in the wet period.

When considering the solar aggressive scenario, the wind capacity was fixed at the initial 730 MW and solar capacity was increased until 875 MW which is a $190 \mathrm{MW}$ addition to the initial solar capacity during wet period. During the high wind period, it could be increased up to 885 MW which is a 200 MW addition. Therefore, in the solar aggressive scenario with 500 MW HVDC, the solar capacity will be limited to $875 \mathrm{MW}$.

Similarly considering the wind aggressive scenario the solar capacity was fixed at the initial $685 \mathrm{MW}$ and the wind capacity was increased. Within the allowable curtailment limits wind capacity could be increased to 810 MW (80 MW addition to initial capacity) during wet period and up to $815 \mathrm{MW}$ (85 MW addition to initial capacity) during the high wind period. Therefore, in the wind aggressive scenario with 500 MW HVDC, the wind capacity will be limited to 810 MW during 2025.

When considering the above two scenarios; solar aggressive with $875 \mathrm{MW}$ solar and $730 \mathrm{MW}$ wind (total of $1605 \mathrm{MW}$ ) and wind aggressive scenario with $685 \mathrm{MW}$ solar and $810 \mathrm{MW}$ wind (total of $1495 \mathrm{MW}$ ), the total renewable energy share including major hydro is $54 \%$. The share of wind and solar energy in solar aggressive scenario is $25 \%$ and in the wind aggressive scenario $26 \%$. Even though the total renewable capacity is lesser in the wind aggressive scenario the energy share is slightly higher than the solar aggressive scenario due to higher plant factor of the wind resource compared to solar.

In the mixed scenario solar and wind capacities were increased up to 795MW solar (addition of $110 \mathrm{MW}$ to the initial capacity) and 780MW wind (addition of 50MW).

Further for the second phase of HVDC development in 2028, only the wet period simulation was carried out to obtain the solar and wind capacity limit.

With the solar aggressive the solar capacity was increased until 910MW which is only 10MW addition to the initial solar capacity and in the wind aggressive scenario the wind capacity was increased to $830 \mathrm{MW}$ which is a $30 \mathrm{MW}$ addition. In both scenarios the total renewable energy share could be increased to $51 \%$ of which solar and wind share was $26 \%$ in solar aggressive scenario and $27 \%$ in wind aggressive scenario.

It was observed that irrespective of the scenario of aggressive solar or wind or mix, the energy share from renewable cannot be increased significantly. Therefore, to achieve a growth in renewable energy share it is wiser to develop a wind aggressive scenario.

It could be observed that the increase in renewable capacity additions with interconnection compared with PSPP is not very significant with the second phase. Therefore the economic analysis was carried out for 500 MW HVDC development and compared with the system with PSPP as described in section 5 .

It was observed that there is a 10.63 USD million reduction of $\mathrm{PV}$ cost in the scenario with interconnecion compared with PSPP at a $10 \%$ discount rate. Table 8 indicates that wind aggressive scenario has the minimum incremental cost and hence becomes the most economical.

When considering the reserve requirement of the power system, the higher penetration of variable renewable energy such as solar and wind brings issues to power system operation which needs to be addressed by providing additional spinning reserve. Developed countries use the statistics based on the forecast error of the intermittent renewable, but Sri Lanka does not yet have such forecasting systems. Therefore, the spinning reserve was kept at $10 \%$ of intermittent capacity for each scenario in addition to $5 \%$ to account for demand fluctuations [17].

\section{Conclusion}

According to the research findings, the following conclusions and recommendations can be made. 
- Solar and wind penetration can be increased with the introduction of HVDC, but at an additional cost to the system based on a variable cost of 70 USD/MWh for imports from India.

- Summary of solar and wind capacities(MW) that can be absorbed to the Sri Lankan power system with the introduction of HVDC interconnection and the comparison with the system with PSPP are given in Table 10.

Table 10: Renewable capacities (MW)

\begin{tabular}{|r|l|r|r|}
\hline & Year & $\mathbf{2 0 2 5}$ & $\mathbf{2 0 2 8}$ \\
\hline & 649 & 719 \\
\hline & & 635 & 850 \\
\hline & Wind & 730 & 800 \\
\hline & Wind & 685 & 900 \\
\hline & Solar & 730, & 800, \\
& $\begin{array}{l}\text { Wind(AS, } \\
\text { AW,Mix) }\end{array}$ & 810,780 & 830,850 \\
\cline { 2 - 4 } & $\begin{array}{l}\text { Solar(AS, } \\
\text { AW,Mix) }\end{array}$ & $\begin{array}{r}875, \\
685,795\end{array}$ & 910, \\
900,905
\end{tabular}

AS-Aggressive Solar, AW-Aggressive Wind, Mix-Solar \& Wind Mix

- From the sensitivity analysis it was found that interconnection is economical for each scenario for variable cost of HVDC as given below.

- Original Scenario 74 USD/MWh (11.0 $\mathrm{LKR} / \mathrm{kWh}$ )

- Solar Aggressive Scenario 45 USD/MWh (7.0 LKR/kWh)

- Wind Aggressive Scenario 54 USD/MWh (8.0 LKR/kWh)

- Mix Scenario 47 USD/MWh (7.2 $\mathrm{LKR} / \mathrm{kWh}$ )

(Exchange Rate used 148 LKR/USD)

This sensitivity analysis could be used when renegotiating the transfer prices during the preparation of financial agreements with India.

- To achieve higher RE share at a comparatively economical cost the wind aggressive scenario is recommended to be implemented.

- It is recommended to introduce day ahead and hourly forecasting system as the level of RE penetration increase, to relax the reserve requirement of $10 \%$ of intermittent renewable capacity.
- It is recommended to implement planned network strengthening project as scheduled, to facilitate RE integration.

- Sri Lanka has a vision of achieving $100 \%$ energy self-sufficiency. In view of that, it is beneficial for the interconnection through HVDC in order to enable the export of any excess electricity generation.

\section{References}

1. CEB statistical digest, 2016

2. http://powermin.nic.in/en/content/overview

3. Greening the Grid: Pathways to Integrate 175 Gigawatts of RenewableEnergy into India's Electric Grid, Vol. I-National Study, A Joint Initiative by USAID and Ministry of Power, India

4. USAID SARI/Energy)/Nexant/PowerGrid, "Viability of Developing a Transmission System Interconnection between India and Sri Lanka Technical Options and Investment Requirements", February 2002.

5. USAID (SARI/Energy)/Nexant/PowerGrid, "Power Transmission Interconnection Prefeasibility study," 2006.

6. Institute of Policy Studies of Sri Lanka in association with Resource Management Associates(Pvt) Ltd and Tiruchelvam Associates, "Supplementary Studies for the Feasibility Study on India-Sri Lanka Grid Interconnection Project," December 2011.

7. Rodrigo, W. D. A. S. et al, "Modeling and transient analysis of HVDC bipolar link," Department of Electrical Engineering, University of Moratuwa, unpublished

8. Jowsick, A. J. M. I. et al, “HVDC transmission line for interconnecting power grids in India and Sri Lanka," Dept. of Electr. \& Electron. Eng., Univ. of Peradeniya, Peradeniya, Sri Lanka, Dec. 2009.

9. Rodrigo, W. A. D. S. and Perera, A. G. C. U. "Dynamic performance of India -Sri Lanka HVDC interconnection: System modeling and simulation," IESL Annual Sessions, Sri Lanka, October 2015.

10. Rodrigo, W. A. D. S. and Perera, A. G. C. U. "Modeling and Simulation of Current Source Converter for Proposed India-Sri Lanka HVDC Interconnection," IEEE, 2015.

11. CEB, Long Term Generation Expansion Plan (LTGEP) 2015-2034， 2015 \& LTGEP 2018-2037, 2018.

12. International Atomic Energy Agency (IAEA), Wien Automatic System Planning (WASP) Package IV, IAEA, 2001. 
13. Japan International Cooperation Agency, Ceylon Electricity Board, Electric Power Development Co., Ltd., “Development Planning on Optimal Power Generation for Peak Demand in Sri Lanka" September 2014.

14. PSR, SDDP User Manual, Version 14.0, February 2016.

15. PSR, NCP Model User Manual, Version 5.16, April 2016.

16. Integration of Renewable Based Generation into Sri Lankan Grid 2017-2028, CEB.

17. Midwest Independent Transmission System Operator (Midwest ISO), ISO/RTO Metrics report, United States, 2010.

\section{Abbreviations}

$\begin{array}{lll}\text { HVDC } & - & \text { High Voltage Direct Current } \\ \text { ORE } & - & \text { Other Renewable Energy } \\ \text { PSPP } & - & \text { Pumped Storage Power Plant } \\ \text { SDDP } & - & \text { Stochastic Dual Dynamic } \\ & & \text { Program } \\ \text { Solar_H } & - & \text { Solar Hambanthota } \\ \text { Solar_K } & - & \text { Solar Kilinochchi } \\ \text { Wind_E } & - & \text { Wind Eastern } \\ \text { Wind_H } & - & \text { Wind Hill country } \\ \text { Wind_M } & - & \text { Wind Mannar } \\ \text { Wind_N } & - & \text { Wind Northern } \\ \text { Wind_P } & - & \text { Wind Puttalam }\end{array}$

